\title{
VERSITA
}

Journal of Official Statistics, Vol. 29, No. 3, 2013, pp. 397-423, DOI: 10.2478/jos-2013-0033

\section{Rapid Estimates of Mexico's Quarterly GDP}

\author{
Víctor M. Guerrero ${ }^{1,2}$, Andrea C. García ${ }^{1}$, and Esperanza Sainz ${ }^{1}$
}

\begin{abstract}
This work presents a procedure for creating a timely estimation of Mexico's quarterly GDP with the aid of Vector Auto-Regressive models. The estimates consider historical GDP data up to the previous quarter as well as the most recent figures available for two relevant indices of Mexican economic activity and other potential predictors of GDP. We obtain two timely estimates of the Grand Economic Activities and Total GDP. Their corresponding delays are at most 15 days and 30 days respectively from the end of the reference quarter, while the first official GDP figure is delayed 52 days. We follow a bottom-up approach that imitates the official calculation procedure applied in Mexico. Empirical validation is carried out with both in-sample simulations and in real time. The mean error of the 30-day delayed estimate of total GDP is $0.13 \%$ and its root mean square error is $0.67 \%$. These figures compare favorably with those of no-change models.
\end{abstract}

Key words: Flash estimates; macroeconomic forecasts; mean square error; timely estimates; time series forecasts; VAR models.

\section{Introduction}

The National Institute of Statistics and Geography, Statistics Mexico (SM) for short, releases quarterly figures of Mexico's Gross Domestic Product or GDP (referred to as PIBT in Spanish) 50-52 days after the end of the reference quarter. In order to analyze the state of the economy in a timely fashion, we propose an estimate delayed no more than 30 days. Our proposal combines the three most important official sources of information: a) the historical record of subsectors of PIBT from the quarterly System of National Accounts (SNA); b) the most recent monthly figures in the databases of the Index of Global Economic Activity (IGAE in Spanish) and the Monthly Index of Industrial Activity (IMAI in Spanish); and c) some general exogenous indicators, mostly from official sources. Section 2 provides more detailed information on IMAI and IGAE.

Our procedure comes as a response to users' demand of timely data for decision making, a need evidenced by the 2008 world financial crisis. In fact, most users prefer timely

1 Dirección General del Servicio Público de Información, Instituto Nacional de Estadística y Geografía (INEGI). Av. Patriotismo 711, Torre "A", Piso 9, Col. San Juan Mixcoac, México 03730, D. F., México. Emails: guerrero@itam.mx, andy18cel@gmail.com and maria.sainz@inegi.org.mx

2 Departamento de Estadística, Instituto Tecnológico Autónomo de México (ITAM). Río Hondo 1, Col. Progreso Tizapán, México 01080, D. F., México.

Acknowledgments: We thank the Associate Editor Christophe Planas and two anonymous referees for detailed and helpful comments that helped us to improve the presentation of this article. This work was facilitated by the useful input and advice of Lourdes Mosqueda from INEGI, who made the databases for the GDP calculation available. Similarly, Blanca R. Sainz, Yuriko Yabuta, Enrique Ordaz and the President of INEGI, Eduardo Sojo, provided the support necessary to carry out this research. Comments and suggestions by Lars-Erik Öller and Gyorgi Gyomai are gratefully acknowledged. V. M. Guerrero participated in this project thanks to a sabbatical year granted by Instituto Tecnológico Autónomo de México (ITAM), to a professorship granted by Asociación Mexicana de Cultura, A. C. and to the generous hospitality of INEGI. 
estimates, even at the expense of precision. Rapid estimates are also called "flash estimates" or "timely estimates" and many international meetings have taken place in order to discuss different issues and technicalities related to this topic, the trade-off between timeliness and precision being of utmost relevance. These meetings have been organized in Ottawa (May 2009), Scheveningen (December 2009) and at the Eurostat headquarters in Luxembourg (September 2010). Some of the most important recommendations that came out of those meetings can be summarized as follows: 1) national statistical agencies should provide rapid estimated figures that make use of official information; 2) such figures should be released at the latest with a 30-day delay; 3) to gain credibility with the users, the estimates should be obtained without relying on a specific economic theory; and 4) the estimation procedure should follow essentially the same approach that is used to calculate the final official figures (see, for instance, Kuzin et al. 2010, Mazzi and Montana 2009, Mazzi et al. 2009, Mustapha and Djolov 2010 and UNECE Secretariat 2009).

The following methods have been used to carry out timely estimation:

i) Bridge equations that relate high frequency data (say monthly) with low frequency (say quarterly) data; for example, Klein and Sojo (1989) predicted quarterly US GDP data from monthly indicators and from disaggregated forecasts of demand components, thus obtaining the total GDP forecast by aggregation. Some other applications of bridge equations appear in Rünstler and Sédillot (2003), Baffigi et al. (2004), Zheng and Rossiter (2006), and Diron (2006).

ii) MIDAS (Mixed Data-frequency Sampling) models that use data with different frequencies of observation, as in Ghysels et al. (2004) and Clements and Galvao (2008), or as in Zadrozny (1990).

iii) Diffusion indices that capture the information of a large number of variables by means of a small number of unobserved common factors, as in Klein and Sojo (1989), who used this technique to obtain a single indicator from a set of 25 monthly indicators. Some other examples are those of Forni and Reichlin (1998) and Stock and Watson (2002). An explanation of this methodology can be found in Armah and Swanson (2008).

iv) Dynamic factor models proposed originally by Geweke (1977) and employed recently by Forni et al. (2005) and Aruoba et al. (2009).

v) Forecast combination that averages forecasts of GDP growth obtained with different regression models, as in Kitchen and Monaco (2003).

We decided not to use method (ii) due to the decisions the analyst has to make when applying it, such as parameterization of the polynomial coefficients involved, appropriate choice of the number of lags and whether or not an autoregressive structure is required (e.g., Clements and Galvao 2008). Besides, the nonlinear estimation procedure involved also imposes a computational burden, since we require a method to be applied to a large number of variables in just one day.

Similarly, methods (iii), (iv) and (v) were discarded because we need an estimate of growth for the three Grand Activities, not just for Total PIBT, in order to enhance the possibilities of analysis. Further, the behaviors of these activities differ markedly, as was verified by Mexican data, and therefore have to be estimated separately. Thus we have chosen bridge equations with a bottom-up approach. This is in accordance with the SNA and 
approaches the estimation from the side of the use of goods and services, thus contrasting with the demand side approach used in the US to calculate flash estimates (see Katz 2006). Moreover, the bridge equations are not used here to link high frequency with low frequency data; instead we propose to use them to link databases with less coverage (IGAE and IMAI) to another one with more coverage (PIBT), though both contain monthly data. The fact that these three databases contain monthly data will be discussed further in Section 2. Since the original databases lack timely information, we resort to time series models to forecast the unobserved variables at the subsector level. Model adequacy is checked using standard econometric tests and predictive ability is analyzed by way of simulations with real time data vintages, as indicated by Koenig et al. (2003). The simulations are carried out with the estimates derived by aggregation to Grand Economic Activities and Total PIBT.

Section 2 presents the decisions made to solve the modeling and forecasting problems that arise because of the large number of subsectors under consideration. We also consider some features of the databases, timeliness and coverage being essential. Section 3 describes the statistical methods employed, particularly the VAR models. In Section 4 we illustrate the application of our method to a group of sectors of tertiary activities. Here, the databases contain the vintage available as of April 2010. We also show some results of the historical simulations and briefly analyze the estimates of the three Grand Activities and Total PIBT. This section also provides an update of the results currently obtained in real time. Section 5 contains some comments and conclusions that focus on the logistics of routine application of the method. The main conclusion of this work is that it is feasible to use reliable and rapid estimates of Mexico's PIBT, one with a 15-day delay and another one delayed at most 30 days, as recommended by the international statistical community. Comparing these estimates to naïve no-change forecasts, we found the former significantly more accurate. The estimation procedure is relatively easy to use and we consider it applicable in other countries that also need rapid GDP estimates.

\section{Grouping of Subsectors and Data Availability}

In Mexico, PIBT is calculated by aggregating the monthly Gross Value Added (GVA) of all classes of economic activity into the GVA of sub-branches, then going up from subbranches to branches, to subsectors, to sectors, to Grand Activities and finally to total GVA. Then the monthly GVA values are added to the quarter to obtain PIBT. Our approach attempts at mimicking the official calculation of PIBT as closely as possible, as recommended in international seminars. However, we start at the subsector level and use a set of decision criteria that allows us to group subsectors as objectively as possible. The classification of economic activities corresponds to production of final goods and services in the country and covers all economic, productive and nonproductive activities, regardless of their profit motives. From here on, we use PIBT and quarterly GVA interchangeably.

According to the North American Industrial Classification System (NAICS) there are 1,051 different classes of economic activity, but only 737 of them are present in Mexico. These classes are grouped into 500 subbranches, 256 branches, 79 subsectors, 20 sectors and three Grand Activities. Due mainly to data availability, at the outset of this study it was decided to start the estimation at the subsector level, that is, estimating the data for groups 
of subsectors (the grouping employed is shown in Appendix A). Three groups correspond to primary activities, nine to secondary activities and 17 to tertiary activities. Those groups of activities will be considered as variables whose outcome will be estimated using statistical models. Instead of the word "estimate" we could have used "forecast", but we retain "estimate" as this is the word preferred by the statistical community and it reflects the fact that our estimates are not only based on historical data.

The following criteria are used to group the subsectors:

(a) Subsector share of total value of the sector (or Grand Activity in some cases), for example the livestock subsector was considered as an individual variable because it represents about $35 \%$ of the GVA of primary activities, although less than $2 \%$ of total GVA.

(b) Impact that the subsector may have on other subsectors; a case in point is mining services. This was taken as a separate variable because it comprises the drilling of wells, an activity that has a direct impact on the subsectors "oil and gas" and "construction of civil engineering works".

(c) Availability of information useful to estimate the subsectors. Several manufacturing subsectors were grouped into one because they lack timely information individually.

(d) Existing relations between different subsectors, such as in the tertiary activities "corporation management and firms" and "businesses support, waste management and remediation services", which are fundamentally related to business activities.

PIBT covers $94 \%$ of annual GDP; exceptions are only series reported annually. PIBT differs from IGAE and IMAI in that it is expressed in monetary units (constant pesos at 2003 prices), whereas IGAE and IMAI are released as indices with the base year 2003. For internal purposes, SM generates the IGAE and IMAI databases expressed as GVA at constant prices. We use such monthly disaggregated information as well as some other monthly variables described below. The IMAI database includes industrial activities of sectors 21 to 33 of the NAICS (2007), that is, all secondary activities. Since there is a 42-day gap between the release of information and the month being reported, we can anticipate the figure of PIBT with a 12-day delay using data on two out of the three months of the quarter, estimating month three using time series models.

The IGAE database complements that of IMAI to achieve almost total coverage of PIBT, since it covers all the subsectors that appear in Appendix A except for the few subsectors indicated there. Besides this, IGAE comprises either one or two months of a quarter and its figure is released 57 days after the end of the month of reference. Its coverage is close to $90 \%$ of that of PIBT and it provides timely figures before the end of every quarter. Hence, its database can be used to predict PIBT with a 27-day delay when two months of IGAE are available for a quarter. The models that use these data are known as c2 models, while i2 models refer to the use of only one month of IGAE and one month of IMAI (or equivalently two months of IGAE, one of which is incomplete). Figure 1 shows the coverage of the databases and the release dates for a given year "a"; there we see that IMAI has nearly $30 \%$ coverage of PIBT, while IGAE's coverage fluctuates around 90\%. The IMAI data appears 42 days after the end of a month, for example the figure of November(a-1) is published in January of year "a" and that of October(a) is published in December of year "a". Similarly the IGAE figures are released 57 days after the end of the reference month, except for October whose figure is released in January. 


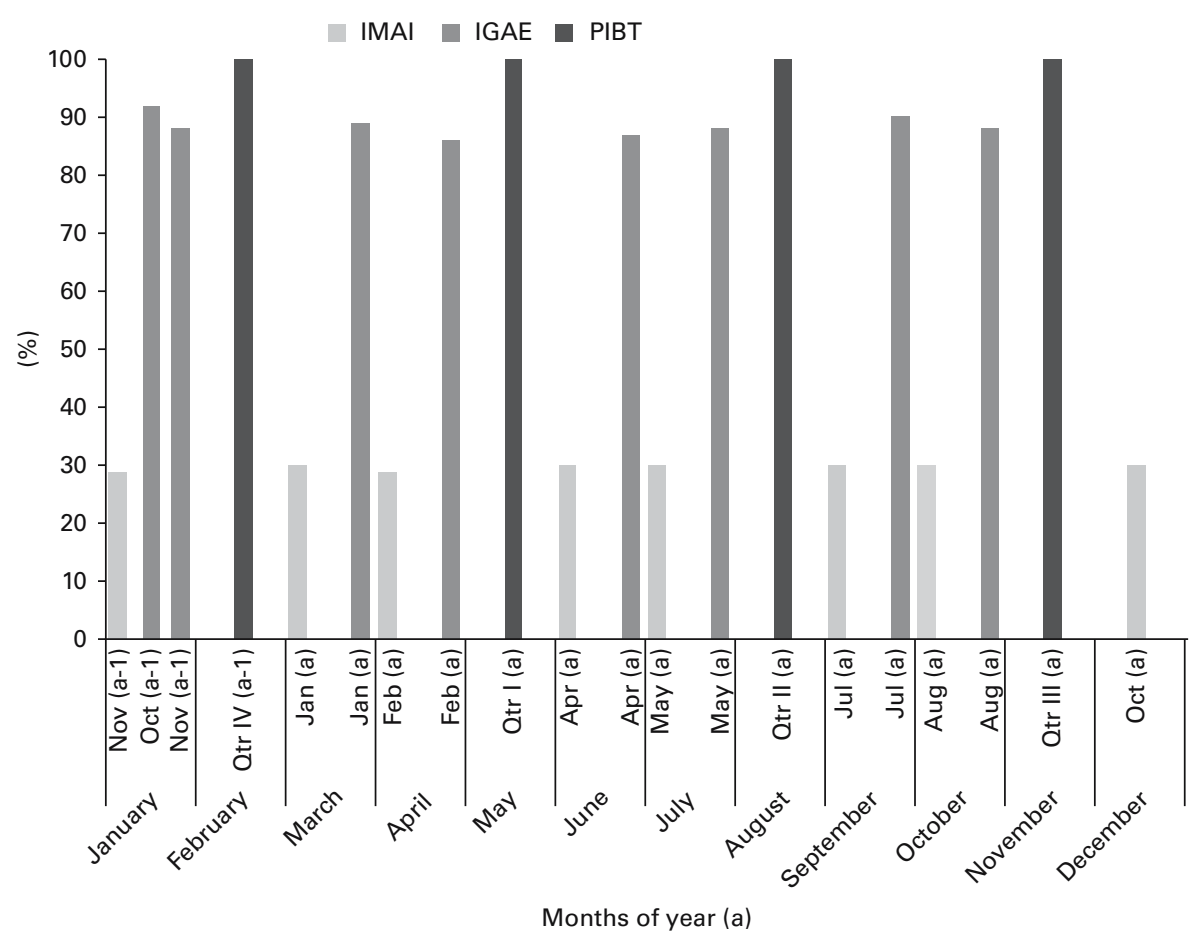

Fig. 1. Months of publication of IMAI, IGAE and PIBT data for a given year " $a$ "

An i2 estimate makes use of $40 \%$ of the basic information available on PIBT $(30 \%$ coming from IGAE and $10 \%$ from IMAI), so that we actually have to estimate $60 \%$ of the Total PIBT unavailable 12 days after the end of the quarter. Similarly, a c2 estimate uses 2 months of IGAE, that is, $60 \%$ of the basic information on PIBT, and therefore we only need to estimate the remaining $40 \%$ unavailable 27 days after the end of the quarter. This of course makes a c 2 estimate more reliable than the corresponding i2 estimate. Some other official databases and information systems provide potential predictors of the variables leading to the PIBT estimate. They are: Monthly Business Opinion Survey; System of Composite Coincident and Leading Indicators; Consumer Confidence Survey; Trade Balance; and National Occupation and Employment Survey. Another source of information employed is that of the Central Bank of Mexico, as well as some other domestic sources. Finally, the models included dummy variables to capture the effect of such events as Easter, the 2009 swine flu epidemics (AH1N1), a leap year, and level shifts due to annual revisions and benchmarking, as recommended by the International Monetary Fund (see Bloem et al. 2001). A schematic view of the steps followed each quarter to obtain the estimates from both Models i2 and c2 can be seen in Appendix B.

\section{Statistical Models and Analysis}

The basic tool that we used to generate forecasts is a VAR model, which can be deemed a reduced form representation of a structural equation system without assuming that an economic theory underlies it. Thus we use these models to capture the empirical 
regularities in the historical record of the multiple time series under consideration, as well as the interdependencies of the endogenous variables it comprises. Moreover, we emphasise here the well-known predictive ability of a VAR model (see Lütkepohl 2005).

A finite order VAR model can be written as

$$
\Pi(\mathrm{B}) \mathbf{Z}_{t}=\Lambda_{0} \mathbf{D}_{t}+\Lambda_{1} \mathbf{X}_{t}+\ldots+\Lambda_{q} \mathbf{X}_{t-q}+\mathbf{a}_{t}
$$

where $\mathbf{Z}_{t}=\left(Z_{1, t}, \ldots, Z_{k, t}\right)^{\prime}$ is a column vector of $k$ endogenous variables observed at time $t=1, \ldots, N, \Pi(\mathrm{B})=\mathrm{I}_{k}-\Pi_{1} \mathrm{~B}-\ldots-\Pi_{p} \mathrm{~B}^{p}$ is a matrix polynomial of order $p<\infty, \mathrm{I}_{k}$ is the identity matrix of order $k$ and $\Pi_{l}, \ldots, \Pi_{p}$ are constant parameter matrices, defined as

$$
\Pi_{j}=\left(\begin{array}{cccc}
\pi_{j, 11} & \pi_{j, 12} & \ldots & \pi_{j, 1 k} \\
\pi_{j, 21} & \pi_{j, 22} & \ldots & \pi_{j, 2 k} \\
\ldots & \ldots & \ldots & \ldots \\
\pi_{j, k 1} & \pi_{j, k 2} & \ldots & \pi_{j, k k}
\end{array}\right) \text { for } j=1, \ldots, p
$$

The vector $\mathbf{D}_{t}=\left(\mathrm{D}_{1, t}, \ldots, \mathrm{D}_{k, t}\right)$ ' contains the deterministic elements, such as the constant and dummy variables for events with potential predictive ability on $\mathbf{Z}_{t}$, while $\mathbf{X}_{t}, \ldots, \mathbf{X}_{t-q}$ are vectors of lagged $(q \geq 0)$ exogenous variables and $\Lambda_{0}, \ldots, \Lambda_{q}$ are constant matrices. Finally, $\left\{\mathbf{a}_{t}\right\}$ is assumed to follow a white noise vector process distributed as $\mathbf{a}_{t} \sim \mathrm{N}_{k}\left(\mathbf{0}_{k}, \Sigma_{a}\right)$, where $\Sigma_{a}$ is a symmetric matrix with diagonal elements $\operatorname{Var}\left(a_{i t}\right)=\sigma_{i}^{2}$ and off-diagonal elements $\operatorname{Cov}\left(a_{i t}, a_{j t}\right)=\sigma_{i, j}$, with $i, j=1, \ldots, k$ and $j \neq i$.

We assume the process is second order stationary and estimate the model by Ordinary Least Squares. We use it to generate optimal, in the sense of minimum Mean Square Error (MSE), linear forecasts conditional on the historical information $\mathbf{Z}=\left(\mathbf{Z}_{1}, \ldots, \mathbf{Z}_{N}\right)^{\prime}$, that is,

$$
\begin{aligned}
\mathrm{E}\left(\mathbf{Z}_{N+1} \mid \mathbf{Z}\right)= & \Pi_{1} \mathbf{Z}_{N}+\ldots+\Pi_{p} \mathbf{Z}_{N+1-p}+ \\
& \Lambda_{0} \mathbf{D}_{N+1}+\Lambda_{1} \mathbf{X}_{N+1}+\ldots+\Lambda_{q} \mathbf{X}_{N+1-q}
\end{aligned}
$$

where the observations of the exogenous variables are assumed to be known. Thus the MSE matrix of the one-step-ahead forecast is

$$
\operatorname{MSE}\left[\mathrm{E}\left(\mathbf{Z}_{N+1} \mid \mathbf{Z}\right)\right]=\operatorname{Var}\left(\mathbf{a}_{N+1} \mid \mathbf{Z}\right)=\Sigma_{a} .
$$

Building VAR models in practice requires first deciding the expression of the variables that will enter the model, bearing in mind that they must be stationary. In our context, the data is seasonally unadjusted, since that is the type of data used to calculate PIBT and it was decided beforehand that a natural expression for the variables had to be like annual (month on month) relative variations, since that is how economic growth is usually interpreted in Mexico. Besides, using seasonally adjusted data would have prevented us from using VAR models, since seasonal adjustment procedures are known to induce noninvertibility of the theoretical models to be employed (see, for instance, Maravall 1993). Hence, it only remained to check whether that transformation produced stationary variables or whether an additional monthly difference had to be used. 
Rather than using unit root tests, we decided to apply the monthly difference to all the variables already expressed as annual variations. This decision was taken because the outcomes of these tests are affected by the presence of deterministic effects and structural changes, as indicated by Enders (2003, ch. 4). In our case it was unclear which effects had to be considered, and such effects change as time goes by. Furthermore, the size and power of individual unit root tests are sensible to the presence of error autocorrelation in the model employed by the test (since the first order autoregressive coefficient and its standard error cannot be estimated appropriately in that case).

Thus, rather than performing unit root tests before building the VAR model, we decided to apply the same degree of differencing to all the variables in the system to be modeled. It is clear that this procedure may produce over-differencing, but this is not as serious a problem as that of under-differencing when the model is built for forecasting purposes. In fact, Sánchez and Peña (2001) argue in favor of over-differencing rather than underdifferencing when using autoregressive models to generate forecasts. Thus, once the model was estimated we checked that the roots of the corresponding determinantal equation were outside the unit circle. A final and very important argument to support our decision is that we were looking for a generic transformation to be applied to all the variables in the different VAR models, because the process is required to be easy to use in routine applications (every quarter) by the personnel at SM.

Therefore, the variables enter the VAR model expressed in general as

$$
Z_{t}=D O^{I G A E} V_{t}=\frac{O_{t}^{I G A E}}{O_{t-12}^{I G A E}}-\frac{O_{t-1}^{I G A E}}{O_{t-13}^{I G A E}}
$$

where $O_{t}^{I G A E}$ is the originally observed variable at time $t$, coming from the IGAE database, $O^{I G A E} V_{t}$ is its annual variation and $D O{ }^{I G A E} V_{t}$ is the monthly difference of the annual variation. It should be clear that we need to apply this transformation to the data in order to build the model, but once the required forecast is obtained we can go back to the original scale with ease by simply applying the inverse transformation. To determine the value $p$ of Model (3.1) we applied sequential likelihood ratio tests. Thus we tested $H_{O}$ : the order is $p$ vs. $H_{A}$ : the order is $p$ - 1 , with $p=4$ as the initial value. We discarded those variables whose estimated coefficient was not significant at the $5 \%$ level and checked for no error autocorrelation with the Ljung-Box multivariate statistic $Q^{*}$.

We considered a univariate equation for AGRIC, because this sector follows a pattern completely different from the other economic activities. Data for this sector refers to an agricultural period that starts in October, while the previous agricultural period ends in March of the following year, so that an overlap of six months occurs between two consecutive agricultural periods. This feature is explained by the fact that the AutumnWinter cycle begins in October and finishes in March of the next year. Harvest usually begins in December and ends the next September. The sowing of the Spring-Summer cycle begins in April and ends in September of the same year, while the first harvest starts in June and finishes in March of the next year.

The model employed is given by

$$
\begin{aligned}
\text { DAGRICV } V_{t}^{I G A E}= & \varphi_{0}+\varphi_{1} D A G R I C V_{t-1}^{I G A E}+\ldots+\varphi_{m} D A G R I C V_{t-m}^{I G A E} \\
& +\beta_{1} D_{1, t}+\ldots+\beta_{r} D_{r, t}+\gamma_{1} X_{1, t}+\ldots+\gamma_{s} X_{s, t}+\varepsilon_{t}
\end{aligned}
$$


with DAGRICV ${ }^{I G A E}$ being the change of the annual variation of AGRIC, with data from the IGAE database. We employed bridge equations to link variables coming from the $I G A E$ database with the monthly GVA for the subsectors with missing data (see Appendix A). The typical form of a bridge equation is

$$
O_{t}^{G V A}=\alpha_{0}+\alpha_{1} \hat{O}_{t}^{I G A E}+\beta_{1} D_{1, t}+\ldots+\beta_{r} D_{r, t}+\gamma_{1} X_{1, t}+\ldots+\gamma_{s} X_{s, t}+\varepsilon_{t}
$$

where $O_{t}^{\mathrm{GVA}}$ is the monthly GVA variable and $\hat{O}_{t}^{\mathrm{IGAE}}$ is the predicted IGAE variable from the VAR model; the $\alpha \mathrm{s}, \beta \mathrm{s}$ and $\gamma \mathrm{s}$ are parameters to be estimated and $r$ is the number of deterministic variables $(D)$ such as trend, seasonality and dummies for calendar effects and interventions. Moreover, $s$ is the number of exogenous or predetermined variables $(X)$ with respect to $O_{t}^{\mathrm{GVA}}$, such as indicator variables of annual level shifts, as well as autoregressive (AR) and moving average (MA) terms. Furthermore, $\left\{\varepsilon_{t}\right\}$ is a sequence of zero-mean nonautocorrelated random errors, in order for Ordinary Least Squares to apply. By using bridge equations we imply that the data for the three months of each quarter have to be estimated.

The statistical models produce forecasts that are considered optimal if they are unbiased and the $h$-period ahead forecast error behaves as an MA $(h-1)$ model, with $h=1,2, \ldots$. (see Diebold 2001, ch. 11). For the VAR models we first obtained the optimal linear forecast with Expression (3.3) and applied the inverse transformation of (3.5) to obtain the forecast in the original scale. The expression used for $\mathrm{c} 2$ models is

$$
\hat{O}_{N+1}^{I G A E}=O_{N-11}^{I G A E}\left(\hat{Z}_{N+1}+O_{N}^{I G A E} / O_{N-12}^{I G A E}\right)
$$

in which case only one month has to be predicted. For i2 models, two months must be predicted and the corresponding expressions are

$$
\begin{aligned}
& \hat{O}_{N+1}^{I G A E}=O_{N-11}^{I G A E}\left(\hat{Z}_{N+1}+O_{N}^{I G A E} / O_{N-12}^{I G A E}\right) \text { and } \\
& \hat{O}_{N+2}^{I G A E}=O_{N-10}^{\mathrm{IGAE}}\left(\hat{Z}_{N+2}+\hat{O}_{N+1}^{\mathrm{IGAE}} / O_{N-11}^{\mathrm{IGAE}}\right) .
\end{aligned}
$$

The forecast is valid for the original variable from the IGAE database in which case $\hat{O}_{N+h}^{\mathrm{GVA}}=\hat{O}_{N+h}^{I G A E}$ for $h=1,2$, when the IGAE database does not lack information on any subsectors. Otherwise, the forecasts from (3.8) and (3.9) are used in the bridge equation (3.7) to obtain the monthly GVA forecast for each month of the quarter. Appendix B provides a schematic view of the estimation procedure employed.

To validate the forecasting ability of our procedure, we carried out nine in-sample simulations (called historical in Appendix C) as well as one out-of-sample (in real time) simulation and analyzed their forecast errors. These were the only possible simulations that could be performed due to data availability. We decided to use a rolling rather than a recursive procedure and produced "the actual forecasts one could make with the model as time progresses" as recommended by Fair and Shiller (1990, p. 376). Thus a six-year rolling window of data was used to estimate the VAR models, because in Mexico there is an approximate six-year cycle in the economy induced by the Presidential elections. Based on this decision we assigned relevance to the most recent information, while still using a sufficiently long stream of data for large sample results to be applicable. 
SM provided data only from the year 2003 onwards, because there was a change of base in that year (PIBT data before 2003 had the base year 1993) and this change of base year involved a new classification of products and activities. There was also an update in concepts and procedures, particularly in the information and communication technology sector. These facts ruled out the possibility of joining the old and new PIBT series (we should recall that we required a complete database, including all subsectors). Appendix C shows the dates associated with the data vintages employed and the type of estimates obtained with those databases. We should also stress that the VAR models and bridge equations generate forecasts of the monthly variables, while the purpose of our procedure is to obtain forecasts of PIBT. Thus what really matters is to evaluate the quarterly forecasts, not the monthly ones.

The following forecast errors refer to the estimated PIBT (that is, $O^{P I B T}$ ) obtained as the average of the monthly GVA figures of the quarter, including the monthly forecasts. In simulation $j$, the one-quarter-ahead forecast error with origin in quarter $T_{j}$ is defined as

$$
e_{T_{j}+1}=O_{T_{j}+1}^{P I B T}-\hat{O}_{T_{j}+1}^{P I B T} \text { for } j=1, \ldots, J .
$$

Note that $T_{j}$ is applicable to quarters, while the subindex $t$ applies to months. We used the following summary measures of forecast errors:

$$
\begin{aligned}
& \text { Mean Error (ME) : } \operatorname{ME}\left(e_{1}\right)=\sum_{j=1}^{J} e_{T_{j}+1} / J \\
& \text { Root Mean Square Error (RMSE): } R M S E\left(e_{1}\right)=\sqrt{\sum_{j=1}^{J} e_{T_{j}+1}^{2} / J} \\
& \text { Theil's U statistic : } \mathrm{U}=\frac{\sum_{j=1}^{J} e_{T_{j}+1}^{2}}{\sum_{j=1}^{J}\left(O_{T_{j}+1}^{\mathrm{PIBT}}-O_{T_{j}+1, n c}^{\mathrm{PIBT}}\right)^{2}}
\end{aligned}
$$

where the alternative naïve forecast involved, $O_{T_{j}+1, n c}^{\mathrm{PIBT}}$, is obtained on the assumption of no-change in the monthly difference of its annual variation, so that it consists of the average of its three monthly values, each of which is calculated as

$$
O_{t_{j}+k, n c}^{G V A}=O_{t_{\mathrm{j}}+k-12}^{G V A}\left(D \bar{O}^{I G A E} V_{k}+O_{t_{j}+k-1}^{I G A E} / O_{t_{j}+k-13}^{I G A E}\right) \text { for } k=1,2,3 .
$$

This expression serves to calculate the no-change one-month-ahead forecast with origin in month $t_{j}$ for $j=1, \ldots, J$ and it is similar to that in (3.8) except that $\hat{Z}$ is now assumed to fluctuate about its mean and is therefore replaced by its average for the corresponding six-year period, $D \bar{O}^{I G A E} V_{k}$. The ratio of variables from the IGAE database available before the end of the quarter indicates the annual change, while the 12-period lagged GVA variable signals the level of the series. In summary, the no-change forecast of PIBT is obtained as

$$
O_{T_{j}+1, n c}^{P I B T}=\sum_{k=1}^{3} O_{t_{j}+k, n c}^{G V A} / 3 .
$$

We do not report the Mean Absolute Error because it provides essentially the same information as the RMSE, as indicated by Granger (1996). A check of predictive ability 
can be done with the Mincer-Zarnowitz regression (see Diebold 2001, ch. 11) to verify that all the information in the dataset employed to obtain the forecast was employed efficiently, that is,

$$
e_{\mathrm{T}_{j}+1}=\eta_{0}+\eta_{1} \hat{O}_{T_{j}+1}^{P I B T}+u_{T_{j}+1}, \text { for } j=1, \ldots, J,
$$

with $\mathrm{u}_{T_{j}+1}$ a non-autocorrelated random error with mean zero and constant variance for all $T_{j}$. Forecast optimality is fulfilled when $\eta_{0}=\eta_{1}=0$.

Another check that can be applied when an alternative forecast exists, as in the present case with the no-change forecast, can be obtained using the regression

$$
O_{T_{j}+1}^{P I B T}=\nu_{1} \hat{O}_{T_{\mathrm{j}}+1}^{P I B T}+\nu_{2} \hat{O}_{T_{j}+1, n c}^{P I B T}+u_{T_{j}+1} \text { for } j=1, \ldots, J
$$

with $\mathrm{u}_{T_{j}+1}$ a random error term, possibly heteroscedastic and autocorrelated. Thus we employed Newey and West's (1987) correction to obtain robust estimates of the standard errors. Now, a forecast-encompassing test is useful to determine whether one of the two forecasts incorporates all the relevant information, as suggested by Fair and Shiller (1990), although Equation (3.17) corresponds to Diebold's (2001, ch. 11) model specification. Thus, if $\nu_{1}=1$ and $\nu_{2}=0$, the proposed forecast incorporates the information of the no-change forecast, and the opposite occurs when $\nu_{1}=0$ and $\nu_{2}=1$. For other values of $\nu_{1}$ and $\nu_{2}$ it is sensible to combine the two forecasts because they both add information.

\section{Numerical Illustration}

To illustrate the results obtained with the proposed methodology, in what follows we describe its application to a group of subsectors of Tertiary Activities, with the database available on April 27, 2010 that includes two sets of monthly data on IGAE (January and February 2010) so that the sample size covers data from 2004:03 to 2010:02 $(N=72)$.

\subsection{Model Estimation Results}

The estimation results shown in Table 1 pertain to the $\mathrm{c} 2$ model VAR31 that includes four endogenous variables of the tertiary sector: COMER (Trade, including sectors 43-46 of NAICS), TRANS (Transportation, with subsectors 481-488), MENS (Messaging, subsectors 491-492) and ALMAC (Warehousing services, subsector 493). Model estimation was carried out using the computer package EViews7 (Econometric Views version 7, Quantitative Micro Software). Due to the large number of estimated parameters appearing in the VAR models (e.g., in the VAR31 model there are 14 coefficients in each of the four equations, eight of which are associated with the lagged endogenous variables, plus the constant and five coefficients associated with the exogenous variables) we summarize the estimation results in Table 1. Here we can see the order of the VAR model $(p)$ as well as the significance achieved by the (transformed) variables in the left column that explain the variability of the (transformed) variables in the upper row.

In Table 1 we see that COMER explains MENS (at the 5\% significance level) and ALMAC (at the $10 \%$ level), but it is not explained by any endogenous variable in the system. The significance levels of the endogenous variables come from $F$ tests for all the lags of the variable under consideration. TRANS explains TRANS, MENS and ALMAC 
Table 1. Estimation results of model VAR31 (with the Apr10c2 database)

\begin{tabular}{lcccc}
\hline$p=2$ & COMER & TRANS & MENS & ALMAC \\
\hline COMER & -- & -- & $* *$ & $*$ \\
TRANS & -- & $* *$ & $* *$ & $* *$ \\
MENS & -- & $*$ & $* * *$ & -- \\
ALMAC & -- & -- & -- & $* *$ \\
ITDEMD & $* * *$ & $* * *$ & $* *$ & -- \\
ICPFPD(-3) & $* * *$ & $* * *$ & $* *$ & $* * *$ \\
BCEV(-1) & -- & -- & $* * *$ \\
SEPUGV(-1) & $* * *$ & & $* *$ & -- \\
\hline$R^{2}(\%)$ & 71.3 & 69.6 & 50.8 & 41.7 \\
$\hat{\sigma}_{\varepsilon}$ & 0.04 & 0.02 & 0.07 & 0.05 \\
$Q^{*}:$ Lags $(p$-value $)$ & $12(0.07)$ & $16(0.13)$ & $20(0.29)$ & $24(0.39)$ \\
\hline
\end{tabular}

Notes: *** indicates significant at the $1 \%$ level, $* *$ at the $5 \%$ level, * at the $10 \%$ level and -- non-significant at the $10 \%$ level.

(with the indicated significance levels) and is explained by itself and MENS; MENS explains TRANS and MENS, and is explained by COMER, TRANS and MENS; ALMAC serves only to explain its own behavior, and is also explained by COMER and TRANS. The exogenous variables are: ITDEMD (annual difference of the Tendency Indicator of Domestic Demand, coming from the Monthly Business Opinion Survey), which explains all the endogenous variables except ALMAC; ICPFPD(-3) (annual difference of the Producer Confidence Indicator for the Future Economic Situation of the Country, also coming from the Business Opinion Survey), which explains all the endogenous variables with its lag of order 3; BCEV(-1) (annual variation of the Trade Balance Exports lagged one period), which explains MENS and ALMAC; and SEPUGV(-1) (annual variation of the Public Sector Budget Expenditures), which explains three of the four endogenous variables with its first lag.

The lower part of Table 1 shows the percent determination coefficients (lying between $41.7 \%$ and $71.3 \%$ ), the residual standard error for each equation (lying between 0.02 and 0.07 ), and the last row presents the joint Ljung-Box $Q *$ statistics for different lags, together with their $p$-values, indicating no residual autocorrelation at the $5 \%$ significance level. We remark that timely data coming from opinion surveys were found very useful to explain the endogenous variables in the VAR models employed. In this illustration, the exogenous variables ITDEMD and ICPFPD come from the Business Opinion Survey.

Figure 2 shows time series plots of the transformed series (DCOMERV, DTRANSV, DMENSV and DALMACV) together with their corresponding forecasts for March 2010. These plots allow us to visualize a reasonably stationary behavior of the transformed series.

The corresponding plots in the original scale appear in Figure 3. Data for months 2004:03 through 2009:12 come from the monthly GVA database. COMER_GVA, MENS_GVA and ALMAC_GVA are estimated directly with model VAR31 and their corresponding data from the IGAE database is shown for the period 2010:01-2010:02, while the value for 2010:03 is estimated. On the other hand, for TRANS_GVA we show the estimated values obtained by way of a bridge equation for 2010:01-2010:03. These plots allow us to see that the series do not have a constant level and therefore are in need of 

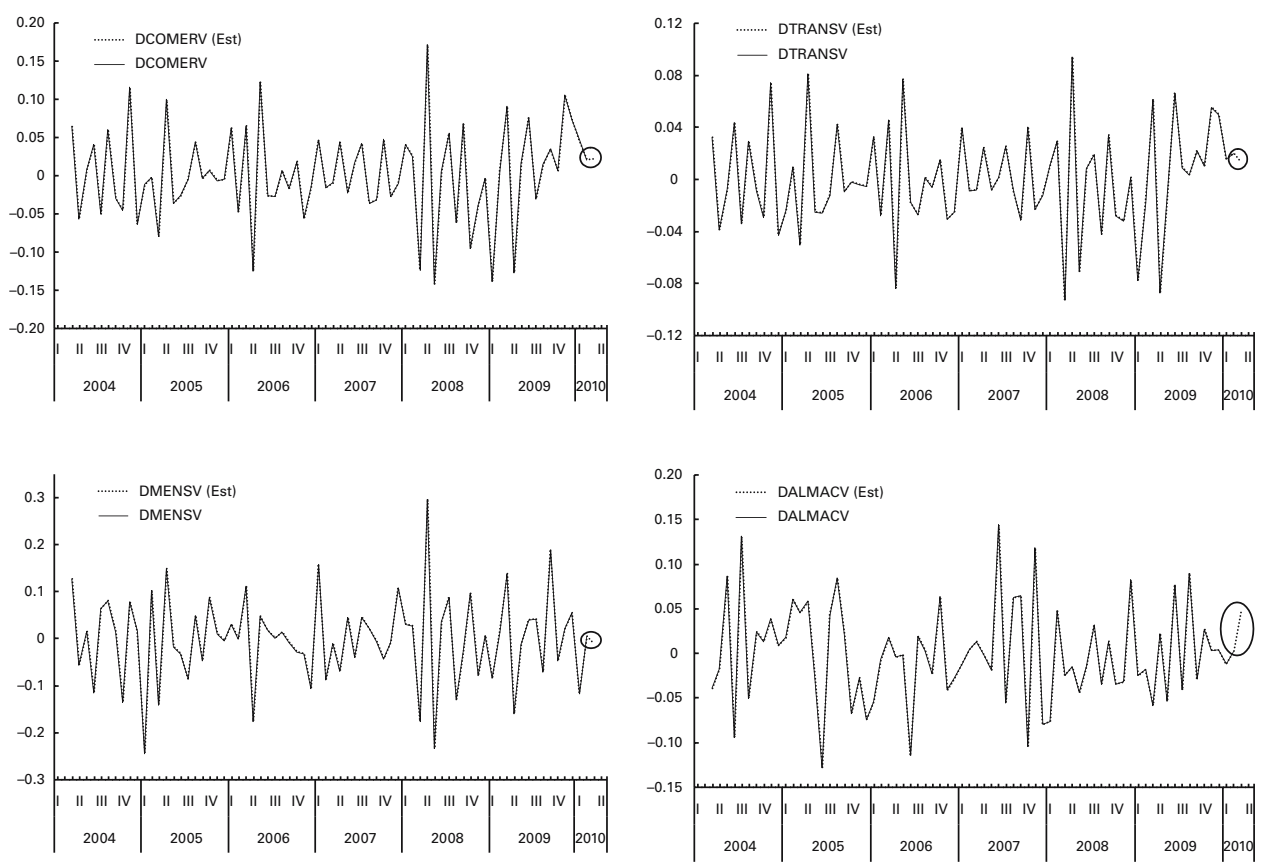

Fig. 2. Monthly transformed variables of model VAR31 from 2004:01 to 2010:02 and estimate for 2010:03

the suggested transformation (the monthly difference of the annual variation) to become approximately stationary. A fall in the level is clearly seen in the upper panels during the last months of 2008 and is less pronounced in the lower panels.

For the VAR31 model, only TRANS requires a bridge equation because subsectors 485 and 488 lack data in the IGAE database, as seen in Appendix A. Figure 4 is useful for appreciating the difference between the series coming from the IGAE and PIBT databases. TRANS_IGAE is the series estimated by the VAR model and contains data up to February 2010, while TRANS_GVA has data up to December 2009 only. Thus, it is necessary to transfer the forecast information from the former to the latter with the aid of a bridge equation that includes a constant, the estimated variable TRANS_IGAE, a dummy variable to account for a level change in year 2005 (A2005) and a moving average term of order 12,

$$
\begin{aligned}
& T R \hat{A} N S_{t}^{G V A}=60,989,103+1.18 T R \hat{A} N S_{t}^{I G A E}-7,844,128 A 2005_{t}+0.85 \mathrm{MA}(12) \\
& (-4.52)
\end{aligned}
$$

$t$ statistics appear in parenthesis and indicate significance at the $1 \%$ level. Moreover, we obtained $R^{2}=97.6 \%, \hat{\sigma}_{\varepsilon}=5,109,454$ and the Ljung-Box statistic $Q *$ : Lags ( $p$-value) $12(0.43), 16(0.30), 20(0.06)$ and 24(0.09), so that there is no evidence of inadequacy.

In the same way as for the VAR31 model, we estimated the VAR11 model with its bridge equation and the autoregressive equation for the variable AGRIC, the VAR21 and VAR22 models that do not need bridge equations, and the VAR32, VAR33 and VAR34 models with their respective bridge equations. 

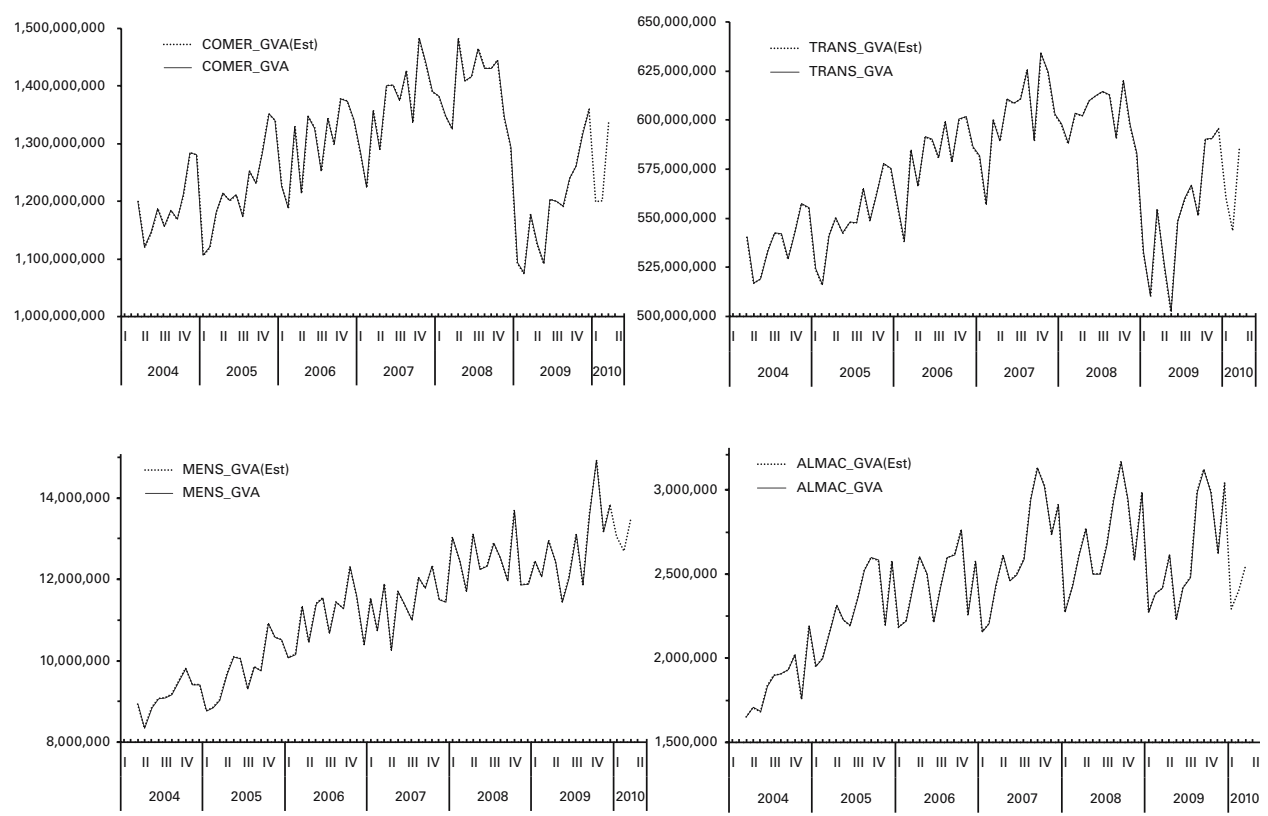

Fig. 3. Variables of the VAR31 model and estimated values in the original scale

\subsection{Forecast Evaluation}

Evaluation of forecast ability of our procedure was done by simulating using the databases available at the time of reference and using the two models, $i 2$ and $\mathrm{c} 2$. Thus nine historical simulations were carried out for quarters 2008:I through 2010:I, as well as one further simulation in real time for quarter 2010:II. Appendix C shows the estimation schedule of

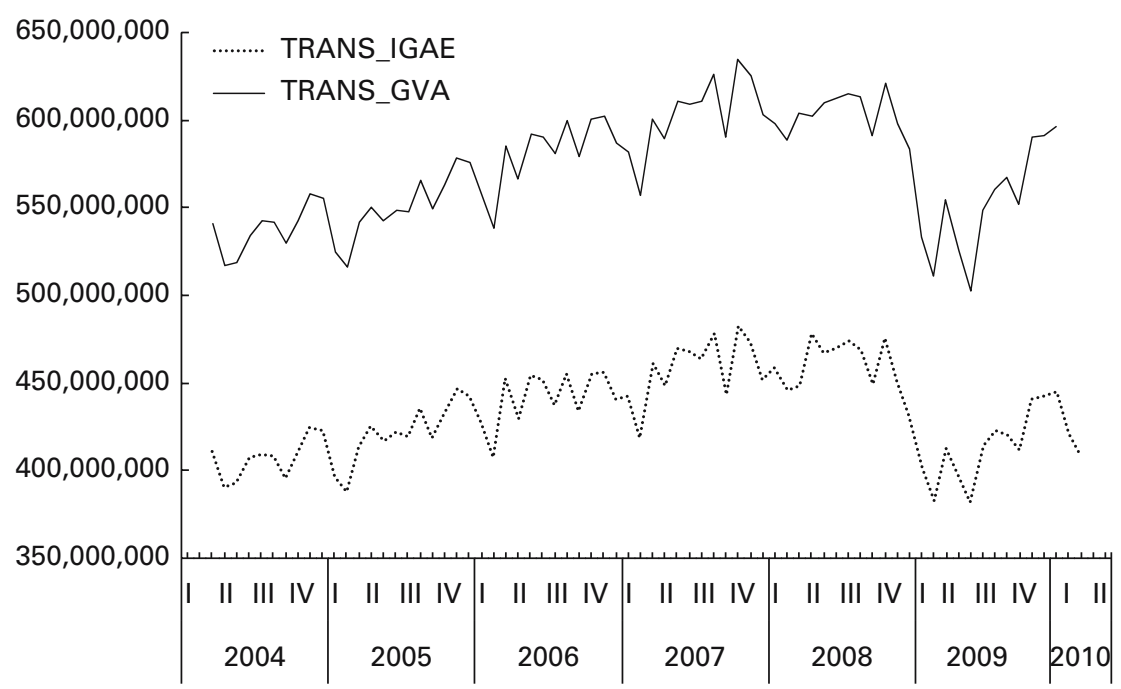

Fig. 4. Original variables TRANS_IGAE from the IGAE database and TRANS_GVA from PIBT 
the simulations and the applicable models. The simulation results are shown in Tables 2 and 3 for the three Grand Economic Activities and Total PIBT.

The original data was expressed in thousands of pesos, but the data appearing in the tables is expressed in millions of pesos for clarity of exposition. In Table 2 we see that the ME of Model c2 for Primary Activities is slightly lower than that for Model i2. By looking at the RMSE we can also state that precision is better for Model c2, but the percent estimation errors in Table 3 show that the RMSEs are too high for both models. For Secondary Activities we see in Table 2 that the ME is slightly lower for Model i2 than for Model c 2 and the RMSE is also slightly better for Model i2, but the percent estimation errors are essentially the same for both models. This is to be expected, since the IMAI and IGAE databases contain basically the same information for Secondary Activities. What should be emphasized is that the RMSEs for Secondary Activities are substantially lower than those

Table 2. Simulation results for each of the Grand Economic Activities and Total PIBT. Millions of pesos at 2003 value

\begin{tabular}{|c|c|c|c|c|c|c|}
\hline \multirow{3}{*}{ Quarter } & \multicolumn{3}{|c|}{ Primary } & \multicolumn{3}{|c|}{ Secondary } \\
\hline & \multirow{2}{*}{$\begin{array}{c}\text { Observed } \\
\text { data }\end{array}$} & \multicolumn{2}{|c|}{ Errors } & \multirow{2}{*}{$\begin{array}{c}\text { Observed } \\
\text { data }\end{array}$} & \multicolumn{2}{|c|}{ Errors } \\
\hline & & i2 model & c2 model & & i2 model & c2 model \\
\hline 2008:I & 285,391 & $-16,980$ & $-19,271$ & $2,653,576$ & $-41,547$ & $-45,492$ \\
\hline 2008:II & 338,570 & 7,830 & $-1,500$ & $2,729,747$ & $-24,411$ & $-11,889$ \\
\hline 2008:III & 295,822 & $-7,491$ & 9,803 & $2,672,789$ & $-3,965$ & $-3,295$ \\
\hline 2008:IV & 360,094 & 18,874 & 6,317 & $2,624,089$ & 36,581 & 52,829 \\
\hline 2009:I & 301,210 & $-24,260$ & $-4,812$ & $2,427,509$ & 16,123 & 22,026 \\
\hline 2009:II & 360,655 & $-13,316$ & $-3,593$ & $2,457,649$ & 21,659 & 17,450 \\
\hline 2009:III & 301,831 & 7,230 & 909 & $2,532,108$ & $-42,667$ & $-42,667$ \\
\hline 2009:IV & 370,113 & 28,222 & 29,415 & $2,591,980$ & $-6,816$ & $-6,816$ \\
\hline 2010:I & 282,657 & 10,121 & 5,923 & $2,547,287$ & 8,149 & 7,733 \\
\hline 2010:II & 365,391 & 12,528 & $-1,330$ & $2,664,219$ & 33,376 & 33,362 \\
\hline $\mathrm{ME}$ & -- & 2,276 & 2,186 & -- & -352 & 2,324 \\
\hline \multirow[t]{2}{*}{ RMSE } & -- & 16,236 & 12,036 & -- & 27,299 & 29,735 \\
\hline & \multicolumn{3}{|c|}{ Tertiary } & \multicolumn{3}{|c|}{ Total PIBT } \\
\hline 2008:I & $5,269,578$ & $-29,332$ & $-35,628$ & $8,208,545$ & $-87,859$ & $-100,390$ \\
\hline 2008:II & $5,448,525$ & $-51,630$ & 36,656 & $8,516,842$ & $-68,211$ & 23,268 \\
\hline 2008:III & $5,527,957$ & 27,345 & 18,389 & $8,496,567$ & 15,888 & 24,897 \\
\hline 2008:IV & $5,496,849$ & $-111,122$ & $-49,285$ & $8,481,031$ & $-55,666$ & 9,861 \\
\hline 2009:I & $4,861,519$ & 124,571 & 70,840 & $7,590,238$ & 116,434 & 88,054 \\
\hline 2009:II & $4,894,911$ & 29,160 & $-75,585$ & $7,713,215$ & 37,503 & $-61,727$ \\
\hline 2009:III & $5,285,423$ & 128,653 & 82,286 & $8,119,362$ & 93,217 & 40,529 \\
\hline 2009:IV & $5,373,928$ & 85,390 & 34,587 & $8,336,021$ & 106,796 & 57,186 \\
\hline 2010:I & $5,093,032$ & 32,344 & 67,047 & $7,922,976$ & 50,613 & 80,703 \\
\hline 2010:II & $5,288,196$ & $-48,668$ & $-67,993$ & $8,297,805$ & $-22,764$ & $-55,961$ \\
\hline $\mathrm{ME}$ & -- & 18,671 & & -- & 18,595 & 10,642 \\
\hline RMSE & -- & 77,619 & 57,617 & -- & 73,390 & 61,203 \\
\hline
\end{tabular}


Table 3. Simulation results for the Grand Economic Activities. Percent estimation errors

\begin{tabular}{|c|c|c|c|c|c|c|c|c|}
\hline \multirow[b]{2}{*}{ Quarter } & \multicolumn{2}{|c|}{ Primary } & \multicolumn{2}{|c|}{ Secondary } & \multicolumn{2}{|c|}{ Tertiary } & \multicolumn{2}{|c|}{ Total PIBT } \\
\hline & $\begin{array}{c}\mathrm{i} 2 \\
\text { model }\end{array}$ & $\begin{array}{c}c 2 \\
\text { model }\end{array}$ & $\begin{array}{c}\text { i2 } \\
\text { model }\end{array}$ & $\begin{array}{c}c 2 \\
\text { model }\end{array}$ & $\begin{array}{c}\text { i2 } \\
\text { model }\end{array}$ & $\begin{array}{c}\mathrm{c} 2 \\
\text { model }\end{array}$ & $\begin{array}{c}\mathrm{i} 2 \\
\text { model }\end{array}$ & $\begin{array}{c}\mathrm{c} 2 \\
\text { model }\end{array}$ \\
\hline 2008:I & -5.95 & -6.75 & -1.57 & -1.71 & -0.56 & -0.68 & -1.07 & -1.22 \\
\hline 2008:II & 2.31 & -0.44 & -0.89 & -0.44 & -0.95 & 0.67 & -0.80 & 0.27 \\
\hline 2008:III & -2.53 & 3.31 & -0.15 & -0.12 & 0.49 & 0.33 & 0.19 & 0.29 \\
\hline 2008:IV & 5.24 & 1.75 & 1.39 & 2.01 & -2.02 & -0.90 & -0.66 & 0.12 \\
\hline 2009:I & -8.05 & -1.60 & 0.66 & 0.91 & 2.56 & 1.46 & 1.53 & 1.16 \\
\hline 2009:II & -3.69 & -1.00 & 0.88 & 0.71 & 0.60 & -1.54 & 0.49 & -0.80 \\
\hline 2009:III & 2.40 & 0.30 & -1.69 & -1.69 & 2.43 & 1.56 & 1.15 & 0.50 \\
\hline 2009:IV & 7.63 & 7.95 & -0.26 & -0.26 & 1.59 & 0.64 & 1.28 & 0.69 \\
\hline 2010:I & 3.58 & 2.10 & 0.32 & 0.30 & 0.64 & 1.32 & 0.64 & 1.02 \\
\hline 2010:II & 3.43 & -0.36 & 1.25 & 1.25 & -0.92 & -1.29 & -0.27 & -0.67 \\
\hline ME & 0.44 & 0.5 & 0.0 & & 0.39 & 0 . & 0.2 & 0.13 \\
\hline RMSE & 4.92 & 3.62 & 1.05 & 1.14 & 1.49 & 1.12 & 0.91 & 0.77 \\
\hline
\end{tabular}

for Primary Activities and there is no appreciable estimation bias. For Tertiary Activities, both the ME and the RMSE are higher for Model i2 than for Model c2, because the latter model includes more timely information than the former. Again, there does not seem to be any estimation bias (an appropriate statistical test is applied below), and the RMSE of Model c2 is reasonably low and comparable with that obtained for Secondary Activities.

Finally, both ME and RMSE for Total PIBT are larger for Model i2 than for Model c2. Precision and lack of bias are better for this variable than for each of the Grand Activities considered separately in both absolute and relative terms. Furthermore, by looking at the MEs we conclude that Primary Activities is the variable with highest estimation bias although nonsignificant at the 5\% level, as shown by the test applied below. Moreover, the RMSEs allow us to appreciate that the Primary Activities estimate has a much lower precision than the other two activities. By contrast, the Total PIBT results are deemed successful because the RMSE for Model c2 is relatively low $(0.77 \%)$ and there is no estimation bias $(0.13 \%)$ as compared with each of the Grand Activities.

Some other comparisons of the estimation results are made in the following section. In order to test for significant estimation bias we used Equation (3.16) and obtained the results

Table 4. Checking for the absence of bias with the Mincer-Zarnowitz equation applied to each of the Grand Economic Activities (in millions of pesos at 2003 value)

\begin{tabular}{cccccc}
\hline Model & Statistic & Primary & Secondary & Tertiary & Total PIBT \\
\hline i2 & $\hat{\eta}_{0}$ & $-10,611$ & 330,100 & $1,029,767$ & $1,141,379$ \\
& $t$ & -0.17 & 1.55 & 2.72 & 2.77 \\
& $\hat{\eta}_{1}$ & 0.0398 & -0.1276 & -0.1931 & -0.1378 \\
& $t$ & 0.20 & -1.55 & -2.67 & -2.73 \\
$\mathrm{c} 2$ & $\hat{\eta}_{0}$ & $-5,766$ & 329,555 & 392,617 & 493,897 \\
& $t$ & -0.13 & 1.37 & 0.91 & 0.98 \\
& $\hat{\eta}_{1}$ & 0.0245 & -0.1265 & -0.0733 & -0.0592 \\
& $t$ & 0.18 & -1.36 & -0.89 & -0.96 \\
\hline
\end{tabular}


in Table 4 for each of the Grand Activities and Total PIBT. Model i2 estimates are significantly biased (at the $5 \%$ level, since the critical point of a student's $t$ distribution with 8 degrees of freedom is 2.31) for Tertiary Activities and Total PIBT, so that the i2 model underestimates these two variables (about $0.39 \%$ and $0.25 \%$, respectively). It should be stressed that Model c2 does not produce significant bias for any economic activity.

\subsection{Comparison with the Forecasts from the No-Change Model}

In order to validate the precision results empirically, we consider an alternative estimation procedure based on a very simple competing model. In fact, we consider a no-change model for the monthly differences of the annual rates of growth. The IGAE database employed for this very simple model contains two complete months of data, and hence they are comparable only with the results provided by the $\mathrm{c} 2$ model. In Table 5 we show the results for the three Grand Economic Activities and Total PIBT with the no-change model.

Table 5. Simulation results with the no-change model for each of the Grand Economic Activities. Millions of pesos at 2003 value

\begin{tabular}{|c|c|c|c|c|c|c|}
\hline \multirow[b]{2}{*}{ Quarter } & \multicolumn{3}{|c|}{ Primary Activities } & \multicolumn{3}{|c|}{ Secondary Activities } \\
\hline & Observed & Error & Error $\%$ & Observed & Error & Error \% \\
\hline 2008:I & 285,391 & 3,767 & 1.32 & $2,653,576$ & $-78,393$ & -2.95 \\
\hline 2008:II & 338,570 & 4,035 & 1.19 & $2,729,747$ & 38,839 & 1.42 \\
\hline 2008:III & 295,822 & 12,915 & 4.37 & $2,672,789$ & $-8,215$ & -0.31 \\
\hline 2008:IV & 360,094 & 44,103 & 12.25 & $2,624,089$ & 140,673 & 5.36 \\
\hline 2009:I & 301,210 & $-8,154$ & -2.71 & $2,427,509$ & 5,603 & 0.23 \\
\hline 2009:II & 360,655 & $-9,269$ & -2.57 & $2,457,649$ & $-32,914$ & -1.34 \\
\hline 2009:III & 301,831 & $-4,985$ & -1.65 & $2,532,108$ & 40,818 & 1.61 \\
\hline 2009:IV & 370,113 & 12,420 & 3.36 & $2,591,980$ & 77,218 & 2.98 \\
\hline 2010:I & 282,657 & $-9,728$ & -3.44 & $2,547,287$ & 54,376 & 2.13 \\
\hline 2010:II & 365,391 & 3,049 & 0.83 & $2,664,219$ & 24,444 & 0.92 \\
\hline $\mathrm{ME}$ & -- & 4,815 & 1.29 & -- & 26,245 & 1.01 \\
\hline \multirow[t]{2}{*}{ RMSE } & -- & 16,055 & 4.61 & -- & 63,094 & 2.41 \\
\hline & \multicolumn{3}{|c|}{ Tertiary Activities } & \multicolumn{3}{|c|}{ Total PIBT } \\
\hline 2008:I & $5,269,578$ & $-81,622$ & -1.55 & $8,208,545$ & $-156,248$ & -1.90 \\
\hline 2008:II & $5,448,525$ & 14,957 & 0.27 & $8,516,842$ & 57,831 & 0.68 \\
\hline 2008:III & $5,527,957$ & 25,033 & 0.45 & $8,496,567$ & 29,733 & 0.35 \\
\hline 2008:IV & $5,496,849$ & 361,597 & 6.58 & $8,481,031$ & 546,373 & 6.44 \\
\hline 2009:I & $4,861,519$ & $-49,445$ & -1.02 & $7,590,238$ & $-51,996$ & -0.69 \\
\hline 2009:II & $4,894,911$ & $-10,121$ & -0.21 & $7,713,215$ & $-52,304$ & -0.68 \\
\hline 2009:III & $5,285,423$ & 165,520 & 3.13 & $8,119,362$ & 201,353 & 2.48 \\
\hline 2009:IV & $5,373,928$ & 113,003 & 2.10 & $8,336,021$ & 202,641 & 2.43 \\
\hline 2010:I & $5,093,032$ & 113,771 & 2.23 & $7,922,976$ & 158,418 & 2.00 \\
\hline 2010:II & $5,288,196$ & $-25,151$ & -0.48 & $8,297,805$ & $-17,659$ & -0.21 \\
\hline $\mathrm{ME}$ & -- & 62,754 & 1.15 & -- & 91,814 & 1.09 \\
\hline RMSE & -- & 139,483 & 2.58 & -- & 209,671 & 2.50 \\
\hline
\end{tabular}


By comparing the MEs of Table 5 with those of Table 2 we see that the no-change model yields higher ME values, indicating a tendency to underestimate PIBT. Moreover, the RMSEs are also higher for the no-change model than for the proposed procedure, lending empirical support to the latter in terms of statistical efficiency. These conclusions are more clearly seen when the errors are expressed as percentages. The no-change estimates for Primary Activities are particularly bad for quarters 2008:III, 2008:IV (with a $12.25 \%$ error that was considered inadmissible), 2009:IV and 2010:I. For Secondary Activities, the particularly bad estimates (those with errors greater than $2 \%$ ) correspond to quarters 2008:I, 2008:IV, 2009:IV and 2010:I, with 5.36\% being the highest error. Similarly, for Tertiary Activities the estimation errors greater than $2 \%$ appeared in quarters 2008:IV, 2009:III, 2009:IV and 2010:I, with 6.58\% as an extremely large error.

We again considered the $2 \%$ threshold for Total PIBT and obtained larger estimation errors in the same quarters as before, the largest being $6.44 \%$. The worst estimate provided by the no-change model is that for quarter 2008:IV, which may be due to the worldwide financial crisis. In Table 6 we can see the Theil's U statistics of our procedure against the nochange model. All these statistics are less than unity, indicating a preference for our procedure as being better for Total PIBT than for each of the Grand Economic Activities. Thus, in terms of precision our proposed procedure is better than the no-change model.

Even though Table 6 shows a clear superiority of our procedure, it was deemed convenient to verify that all the relevant information was employed, otherwise we would be able to improve on the estimation by combining the two estimates at hand. To that end we used the encompassing test based on Equation (3.17). Table 7 shows the estimation results of that equation for each of the Grand Economic Activities. There, we confirm that the proposed procedure contains the information provided by the no-change model, since the corresponding calculated $t$ statistics with eight degrees of freedom for that model are smaller than the critical point at the 5\% significance level (2.31), except for tertiary activities. On the contrary, the $t$ statistics for the $\mathrm{c} 2$ model are all significant at the 5\% level. Thus, the naïve model does not contribute any useful information to the estimation in our procedure and there is no reason to combine the two estimates. Notice that the $\hat{\nu}_{1}$ values for Secondary Activities and Total PIBT are very close to unity, which is to be expected for a good estimate; in fact, when we tested the hypothesis $H_{0}: \nu_{1}=1$, we did not reject it in any of the four cases (even in the extreme case of Primary Activities the $t$ statistic took on the value 1.33).

\subsection{Comparing the Estimation Errors Against PIBT Revisions}

In order to judge the magnitude of the estimation errors we compare them with the revisions of PIBT carried out each subsequent quarter at SM. In Tables 8 to 11 we show the

Table 6. Root mean square errors and Theil's U statistics to compare the proposed procedure with the no-change model. Grand Economic Activities in millions of pesos at 2003 value

\begin{tabular}{lccrr}
\hline Method & Primary & Secondary & Tertiary & Total PIBT \\
\hline Proposal & $12,035.8$ & $29,735.5$ & $57,617.0$ & $61,203.0$ \\
No-change & $16,055.4$ & $63,093.6$ & $139,483.0$ & $211,247.3$ \\
Theil's U & 0.56 & 0.22 & 0.17 & 0.09 \\
\hline
\end{tabular}


Table 7. Validating the predictive ability of the proposed procedure. Grand Economic Activities

\begin{tabular}{lcccrr}
\hline Model & Statistic & Primary & Secondary & Tertiary & Total PIBT \\
\hline c2 & $\hat{\nu}_{1}$ & 0.69 & 0.99 & 0.85 & 1.03 \\
$v s$. & $t$ & 2.09 & 4.02 & 14.74 & 10.51 \\
No- & $\hat{\nu}_{2}$ & 0.32 & 0.01 & 0.16 & -0.03 \\
change & $t$ & 0.98 & 0.03 & 2.67 & -0.32 \\
\hline
\end{tabular}

revisions as well as its difference in percentage terms (Revision \%). In Mexico, PIBT is also subjected to other revisions (e.g., every year), but the quarterly revisions are the most important for an analysis of the current state of the economy. Hence, we compare those revisions with the estimates coming from the $\mathrm{c} 2$ model.

Tables 8 to 11 show a systematic pattern in which the first revision is smaller than the second one and the second revision in turn is smaller than the third one, except in quarter 2009:II for Primary Activities and quarter 2009:I for Total PIBT. In these tables we see that in a given year the following revisions are made:

Quarter I: $\mathrm{I}_{1}=\operatorname{Rev}_{1}(\mathrm{I}), \mathrm{I}_{2}=\operatorname{Rev}_{1}\left(\mathrm{I}_{1}\right)=\operatorname{Rev}_{2}(\mathrm{I}), \mathrm{I}_{3}=\operatorname{Rev}_{1}\left(\mathrm{I}_{2}\right)=\operatorname{Rev}_{2}\left(\mathrm{I}_{1}\right)=$ $\operatorname{Rev}_{3}(\mathrm{I})$;

Quarter II: $\mathrm{II}_{1}=\operatorname{Rev}_{1}(\mathrm{II}), \mathrm{II}_{2}=\operatorname{Rev}_{1}\left(\mathrm{II}_{1}\right)=\operatorname{Rev}_{2}(\mathrm{II})$; and Quarter III: $\mathrm{III}_{1}=$ $\operatorname{Rev}_{1}(\mathrm{III})$.

Thus, we have six one quarter behind revisions (revisions of type $\operatorname{Rev}_{1}(\mathrm{X})$, with $\mathrm{X}$ a given quarter), three two quarter behind revisions (revision of type $\operatorname{Rev}_{2}(X)$ ) and one three quarter behind revision (revision of type $\operatorname{Rev}_{3}(X)$ ). This way, for the years and quarters in our sample we have 13 type $\operatorname{Rev}_{1}(X)$ revisions, six type $\operatorname{Rev}_{2}(X)$ and two type $\operatorname{Rev}_{3}(X)$, from which we obtain the summary of results shown in Table 12. The differences attributable to revisions are expressed as percentages in order to compare them with the estimation errors of our procedure.

In Table 12 we see that all the MEs are positive, indicating that revisions tend to increase the GVA for all the economic activities. A similar pattern was seen for the estimation errors for both i2 and c2 models (see Tables 2 and 3). We also see that higher percentage revisions occur for Primary Activities and for Secondary Activities, both in

Table 8. PIBT revisions in subsequent quarters after publication. Primary Economic Activities. Millions of pesos at 2003 value

\begin{tabular}{lccccccc}
\hline Quarter & $\begin{array}{c}\text { Observed } \\
\text { data }\end{array}$ & $\begin{array}{c}\text { First } \\
\text { revision }\end{array}$ & $\begin{array}{c}\text { Revision } \\
\%\end{array}$ & $\begin{array}{c}\text { Second } \\
\text { revision }\end{array}$ & $\begin{array}{c}\text { Revision } \\
\%\end{array}$ & $\begin{array}{c}\text { Third } \\
\text { revision }\end{array}$ & $\begin{array}{c}\text { Revision } \\
\%\end{array}$ \\
\hline 2008:I & 285,391 & 285,915 & 0.18 & 286,298 & 0.32 & 297,083 & 4.10 \\
2008:II & 338,570 & 342,337 & 1.11 & 356,568 & 5.32 & -- & -- \\
2008:III & 295,822 & 298,967 & 1.06 & -- & -- & -- & -- \\
2008:IV & 360,094 & -- & -- & -- & -- & -- & -- \\
2009:I & 301,210 & 301,451 & 0.08 & 299,714 & -0.50 & 297,247 & -1.32 \\
2009:II & 360,655 & 366,265 & 1.56 & 362,506 & 0.51 & -- & -- \\
2009:III & 295,419 & 296,961 & 0.52 & -- & -- & -- & -- \\
2009:IV & 370,113 & -- & -- & -- & -- & -- & -- \\
2010:I & 282,657 & 281,669 & -0.35 & -- & -- & -- & -- \\
\hline
\end{tabular}


Table 9. PIBT revisions in subsequent quarters after publication. Secondary Economic Activities. Millions of pesos at 2003 value

\begin{tabular}{lccccccc}
\hline Quarter & $\begin{array}{c}\text { Observed } \\
\text { data }\end{array}$ & $\begin{array}{c}\text { First } \\
\text { revision }\end{array}$ & $\begin{array}{c}\text { Revision } \\
\%\end{array}$ & $\begin{array}{c}\text { Second } \\
\text { revision }\end{array}$ & $\begin{array}{c}\text { Revision } \\
\%\end{array}$ & $\begin{array}{c}\text { Third } \\
\text { revision }\end{array}$ & $\begin{array}{c}\text { Revision } \\
\%\end{array}$ \\
\hline 2008:I & $2,653,576$ & $2,654,331$ & 0.03 & $2,658,227$ & 0.18 & $2,694,726$ & 1.55 \\
2008:II & $2,729,747$ & $2,730,294$ & 0.02 & $2,778,339$ & 1.78 & -- & -- \\
2008:III & $2,672,789$ & $2,712,285$ & 1.48 & -- & -- & -- & -- \\
2008:IV & $2,624,089$ & -- & -- & -- & -- & -- & -- \\
2009:I & $2,427,509$ & $2,429,546$ & 0.08 & $2,429,901$ & 0.10 & $2,416,358$ & -0.46 \\
2009:II & $2,457,649$ & $2,459,517$ & 0.08 & $2,453,219$ & -0.18 & -- & -- \\
2009:III & $2,532,108$ & $2,522,487$ & -0.38 & -- & -- & -- & -- \\
2009:IV & $2,591,980$ & -- & -- & -- & -- & -- & -- \\
2010:I & $2,547,287$ & $2,547,909$ & 0.02 & -- & -- & -- & -- \\
\hline
\end{tabular}

terms of MEs or RMSEs. However, the reasons for such revisions are different: for Primary Activities there is a lack of data and any new piece of information may substantially change what was already published, while for Secondary Activities there is a great deal of timely data and the database is continually updated.

We can also observe an increase in the percentages by going from one quarter behind revisions to two quarter behind and three quarter behind revisions. Nevertheless, since there are more one quarter behind revisions than other types of revisions, we cannot trust all of them equally and thus we prefer to look at the present results only as indicative of what should be studied more deeply in future work focusing on revisions of PIBT. By looking at the RMSEs in Table 12 we appreciate a decrease in magnitude from Primary Activities to Total PIBT as in Tables 2 and 3. Moreover, the proportion of the third revision with respect to the estimation error of our procedure is 0.8 for Primary Activities, 1.0 for Secondary Activities, 0.4 for Tertiary Activities and 0.7 for Total PIBT, so that our estimates are as precise as the third revision for Secondary Activities. Similarly, our estimates for Primary Activities are slightly less precise than the third revision; the same thing happens with Total PIBT, and the lowest precision occurs when estimating Tertiary Activities.

Table 10. PIBT revisions in subsequent quarters after publication. Tertiary Economic Activities. Millions of pesos at 2003 value

\begin{tabular}{lccccccc}
\hline Quarter & $\begin{array}{c}\text { Observed } \\
\text { data }\end{array}$ & $\begin{array}{c}\text { First } \\
\text { revision }\end{array}$ & $\begin{array}{c}\text { Revision } \\
\%\end{array}$ & $\begin{array}{c}\text { Second } \\
\text { revision }\end{array}$ & $\begin{array}{c}\text { Revision } \\
\%\end{array}$ & $\begin{array}{c}\text { Third } \\
\text { revision }\end{array}$ & $\begin{array}{c}\text { Revision } \\
\%\end{array}$ \\
\hline 2008:I & $5,269,578$ & $5,268,424$ & -0.02 & $5,259,868$ & -0.18 & $5,277,294$ & 0.15 \\
2008:II & $5,448,525$ & $5,441,312$ & -0.13 & $5,458,024$ & 0.17 & -- & -- \\
2008:III & $5,527,957$ & $5,537,215$ & 0.17 & -- & -- & -- & -- \\
2008:IV & $5,496,849$ & -- & -- & -- & -- & -- & -- \\
2009:I & $4,861,519$ & $4,874,842$ & 0.27 & $4,885,200$ & 0.49 & $4,892,965$ & 0.65 \\
2009:II & $4,894,911$ & $4,900,607$ & 0.12 & $4,913,207$ & 0.37 & -- & -- \\
2009:III & $5,192,144$ & $5,198,930$ & 0.13 & -- & -- & -- & -- \\
2009:IV & $5,373,928$ & -- & -- & -- & -- & -- & -- \\
2010:I & $5,093,032$ & $5,093,048$ & 0.00 & -- & -- & -- & -- \\
\hline
\end{tabular}


Table 11. PIBT revisions in subsequent quarters after publication. Total PIBT. Millions of pesos at 2003 value

\begin{tabular}{lccccccc}
\hline Quarter & $\begin{array}{c}\text { Observed } \\
\text { data }\end{array}$ & $\begin{array}{c}\text { First } \\
\text { revision }\end{array}$ & $\begin{array}{c}\text { Revision } \\
\%\end{array}$ & $\begin{array}{c}\text { Second } \\
\text { revision }\end{array}$ & $\begin{array}{c}\text { Revision } \\
\%\end{array}$ & $\begin{array}{c}\text { Third } \\
\text { revision }\end{array}$ & $\begin{array}{c}\text { Revision } \\
\%\end{array}$ \\
\hline 2008:I & $8,208,545$ & $8,208,671$ & 0.00 & $8,204,393$ & -0.05 & $8,269,103$ & 0.74 \\
2008:II & $8,516,842$ & $8,513,943$ & -0.03 & $8,592,930$ & 0.89 & -- & -- \\
2008:III & $8,496,567$ & $8,548,467$ & 0.61 & -- & -- & -- & -- \\
2008:IV & $8,481,031$ & -- & -- & -- & -- & -- & -- \\
2009:I & $7,590,238$ & $7,605,840$ & 0.21 & $7,614,814$ & 0.32 & $7,606,570$ & 0.22 \\
2009:II & $7,713,215$ & $7,726,389$ & 0.17 & $7,7289,320$ & 0.20 & -- & -- \\
2009:III & $8,019,672$ & $8,018,378$ & -0.02 & -- & -- & -- & -- \\
2009:IV & $8,336,021$ & -- & -- & -- & -- & -- & -- \\
2010:I & $7,922,976$ & $7,922,626$ & -0.00 & -- & -- & -- & -- \\
\hline
\end{tabular}

\subsection{An Update for Quarters 2010:III to 2011:IV}

Since the procedure has been applied in a routinely manner, the results in Tables 13 and 14 complement those of Tables 2 and 3. The ME and RMSE measures in the new tables were obtained with data from 2008:I to 2011:IV and show a decrease of the RMSE for Model c2, especially for Total PIBT (from $0.77 \%$ in Table 3 to $0.67 \%$ in Table 14). These results lend further empirical support to our suggested procedure.

\section{Final Comments}

The proposed estimation procedure starts every quarter as soon as the IMAI and IGAE data is released, 12 and 27 days after the end of the reference quarter respectively. In order to do this, the exogenous variables already have to be updated in the databases and once the data is in the form required by the models it is possible to estimate them with a six-year rolling window of data. The underlying assumptions of the models have to be verified and their specifications changed if necessary. The first models to be estimated for a given quarter are of type i2 and their most recent specifications are those of the $\mathrm{c} 2$ models for the previous quarter. Therefore, the i2 specification incorporates three additional months of data, during which time the economic system may have undergone abrupt changes, whereas the $\mathrm{c} 2$ specification is simpler because it is carried out only 15 days after the most recent i2 estimation and only a few data updates occur.

Table 12. Summary of the quarterly percent revisions for the Grand Economic Activities

\begin{tabular}{lcccc}
\hline Revision type & Primary $\%$ & Secondary $\%$ & Tertiary $\%$ & Total PIBT \% \\
\hline & & ME & \\
$\operatorname{Rev}_{1}(X)$ & 0.59 & 0.19 & 0.08 & 0.13 \\
$\operatorname{Rev}_{2}(X)$ & 1.36 & 0.48 & 0.23 & 0.35 \\
$\operatorname{Rev}_{3}(X)$ & 1.39 & 0.55 & 0.40 & 0.48 \\
& & RMSE & & \\
$\operatorname{Rev}_{1}(X)$ & 0.86 & 0.58 & 0.15 & 0.25 \\
$\operatorname{Rev}_{2}(X)$ & 2.77 & 0.99 & 0.32 & 0.50 \\
$\operatorname{Rev}_{3}(X)$ & 3.04 & 1.14 & 0.47 & 0.54 \\
\hline
\end{tabular}


Table 13. Simulation results for each of the Grand Economic Activities and Total PIBT. Millions of pesos at 2003 value

\begin{tabular}{|c|c|c|c|c|c|c|}
\hline \multirow{3}{*}{ Quarter } & \multicolumn{3}{|c|}{ Primary } & \multicolumn{3}{|c|}{ Secondary } \\
\hline & \multirow{2}{*}{$\begin{array}{c}\text { Observed } \\
\text { data }\end{array}$} & \multicolumn{2}{|c|}{ Errors } & \multirow{2}{*}{$\begin{array}{c}\text { Observed } \\
\text { data }\end{array}$} & \multicolumn{2}{|c|}{ Errors } \\
\hline & & i2 model & c2 model & & i2 model & c 2 model \\
\hline 2010:III & 298,073 & 449 & $-8,796$ & $2,688,324$ & $-7,349$ & $-7,060$ \\
\hline 2010:IV & 371,926 & 15,708 & 7,261 & $2,718,258$ & 946 & 114 \\
\hline 2011:I & 287,045 & $-13,557$ & 191 & $2,684,995$ & 32,940 & 32,905 \\
\hline 2011:II & 328,311 & $-19,067$ & $-17,529$ & $2,750,829$ & -892 & -837 \\
\hline 2011:III & 311,353 & 9,631 & $-4,593$ & $2,772,088$ & 11,652 & 11,651 \\
\hline 2011:IV & 337,429 & $-36,673$ & $-6,579$ & $2,799,920$ & 23,620 & 23,623 \\
\hline $\mathrm{ME}$ & -- & $-1,297$ & -511 & -- & 3,587 & 5,227 \\
\hline \multirow[t]{2}{*}{ RMSE } & -- & 17,443 & 11,041 & -- & 24,092 & 25,823 \\
\hline & \multicolumn{3}{|c|}{ Tertiary } & \multicolumn{3}{|c|}{ Total PIBT } \\
\hline 2010:III & $5,507,938$ & 112,567 & 44,867 & $8,494,335$ & 105,667 & 29,011 \\
\hline 2010:IV & $5,666,809$ & 7,913 & $-21,707$ & $8,756,994$ & 24,567 & $-14,332$ \\
\hline 2011:I & $5,362,853$ & 68,021 & 29,238 & $8,334,892$ & 87,404 & 62,335 \\
\hline 2011:II & $5,507,979$ & $-12,689$ & $-42,741$ & $8,587,119$ & $-32,649$ & $-61,107$ \\
\hline 2011:III & $5,746,740$ & 11,340 & 21,791 & $8,830,181$ & 32,623 & 28,850 \\
\hline 2011:IV & $5,880,205$ & 33,607 & 2,001 & $9,017,554$ & 20,554 & 19,046 \\
\hline $\mathrm{ME}$ & -- & 25,467 & 7,173 & -- & 26,507 & 10,639 \\
\hline RMSE & -- & 70,280 & 49,271 & -- & 68,840 & 54,383 \\
\hline
\end{tabular}

The procedure does not allow calculation of variances for the estimates, because model estimation is not carried out simultaneously but for separate groups of variables. An important line of future work would consider solving this deficiency. Another possibility for future methodological research that may improve the forecasting ability of the models lies in recognizing that the transformations applied to stationarize the series are monotonic

Table 14. Simulation results for the Grand Economic Activities. Percent estimation errors

\begin{tabular}{|c|c|c|c|c|c|c|c|c|}
\hline \multirow[b]{2}{*}{ Quarter } & \multicolumn{2}{|c|}{ Primary } & \multicolumn{2}{|c|}{ Secondary } & \multicolumn{2}{|c|}{ Tertiary } & \multicolumn{2}{|c|}{ Total PIBT } \\
\hline & $\begin{array}{c}\mathrm{i} 2 \\
\text { model }\end{array}$ & $\begin{array}{c}\mathrm{c} 2 \\
\text { model }\end{array}$ & $\begin{array}{c}\mathrm{i} 2 \\
\text { model }\end{array}$ & $\begin{array}{c}\mathrm{c} 2 \\
\text { model }\end{array}$ & $\begin{array}{c}\mathrm{i} 2 \\
\text { model }\end{array}$ & $\begin{array}{c}\mathrm{c} 2 \\
\text { model }\end{array}$ & $\begin{array}{c}\mathrm{i} 2 \\
\text { model }\end{array}$ & $\begin{array}{c}\mathrm{c} 2 \\
\text { model }\end{array}$ \\
\hline 2010:III & 0.15 & -2.95 & -0.27 & -0.26 & 2.04 & 0.81 & 1.24 & 0.34 \\
\hline 2010:IV & 4.22 & 1.95 & 0.03 & 0.00 & 0.14 & -0.38 & 0.28 & -0.16 \\
\hline 2011:I & -4.72 & 0.07 & 1.23 & 1.23 & 1.27 & 0.55 & 1.05 & 0.75 \\
\hline 2011:II & -5.81 & -5.34 & -0.03 & -0.03 & -0.23 & -0.78 & -0.38 & -0.71 \\
\hline 2011:III & 3.09 & -1.48 & 0.42 & 0.42 & 0.20 & 0.38 & 0.37 & 0.33 \\
\hline 2011:IV & -10.87 & -1.95 & 0.84 & 0.84 & 0.57 & 0.03 & 0.23 & 0.21 \\
\hline ME & -0.60 & -0.28 & 0.14 & 0.20 & 0.49 & 0.14 & 0.33 & 0.13 \\
\hline RMSE & 5.26 & 3.34 & 0.92 & 0.99 & 1.33 & 0.95 & 0.84 & 0.67 \\
\hline
\end{tabular}


and nonlinear. Thus, by back-transforming to the original scale we induce some bias in the estimation that may be corrected, at least approximately, as in Guerrero (1993). Recently, Ghysels (2012) generalized the MIDAS approach to a Vector Auto-Regressive (VAR) setting and since such an approach is in line with ours, we should try it in future work.

The main conclusion of this work is that not only can we obtain timely estimates of Mexico's PIBT, but the resulting estimates are reasonably precise, as indicated by the comparison criteria employed. It is also clear that the 15-day delay estimate of Secondary Economic Activities PIBT is more precise than the estimates of the other two Grand Economic Activities. With a 30-day delay, the estimate of Secondary Activities remains reasonably precise and we can also obtain a good estimate of Tertiary Economic Activities. However, there is room for improvement in the Primary and Tertiary Activities estimates and some additional effort has to be made to obtain more useful and timely information for the sectors involved in those activities. Thus, we advise SM to make some extra effort to improve the data collection in the agriculture sector and design opinion surveys to collect anticipatory data in the commerce and service sectors.

An advantage of the indirect approach employed here is that we could improve on the estimation of one of the Grand Activities without any need to modify the estimation of the other two. Nevertheless, it should be emphasized that the estimate of Total PIBT is reasonably good and better than each of the Grand Economic Activities estimates considered separately, both for the 15-day and 30-day delay estimation. The people in charge of operating the timely estimation system must be alert to the possibility of having access to more timely data and to some other useful indicators not yet employed by the models considered in this work in the future. 
Appendix A. Grouping of Subsectors, With NAICS Codes. Taken from INEGI (2007)

\section{Primary Activities}

AGRIC (111) - Agriculture

GANAD (112) - Animal breeding and production

FOPEC* $(113-115)$ - Forestry, logging, fishing and hunting

Secondary Activities

EXPYG (211) - Oil and gas extraction

MINER (212) - Mining

SEMIN (213) - Services related to mining

ELAGA (221-222) - Electric power generation, water and gas supply

CONST (236-238) - Construction

FDPYC (324) - Manufacturing of products derived from petroleum and coal

INQUI (325) - Chemical industry

FETRA (336) - Transportation equipment manufacturing

MANUF (311-316, 321-323, 326-327, 331-335, 337, 339) -

Other manufacturing activities

Tertiary Activities

COMER (43-46) - Trade

TRANS* (481-488) - Transportation

MENS (491-492) - Messaging

ALMAC (493) - Warehousing services

TELEC* $(511-512,515-516,518-519)$ - Mass media communication

OTELE* (517) - Other telecommunications

SEFIN* $(521-524)-$ Financial and insurance services

SEINM* (531-533) - Real estate services and goods rental

SEPRO* (541) - Professional, scientific and technical services

CONED* $(551,561-562)$ - Head offices and business support services

SEDUC (611) - Educational services

SESAL* (621-624) - Health care and social assistances services

SEREC (711-713) - Recreation services

SEHOR (721-722) - Temporary accommodation services

SEOT* $(811-814)$ - Other services

ACGOB* (931) - Government activities

SIFMI - Financial intermediation services indirectly measured

*These variables lack information on some subsectors and require the use of bridge equations. 
Appendix B. Estimation Procedure Employed for Models i2 and c2 in a given Year " $a$ "

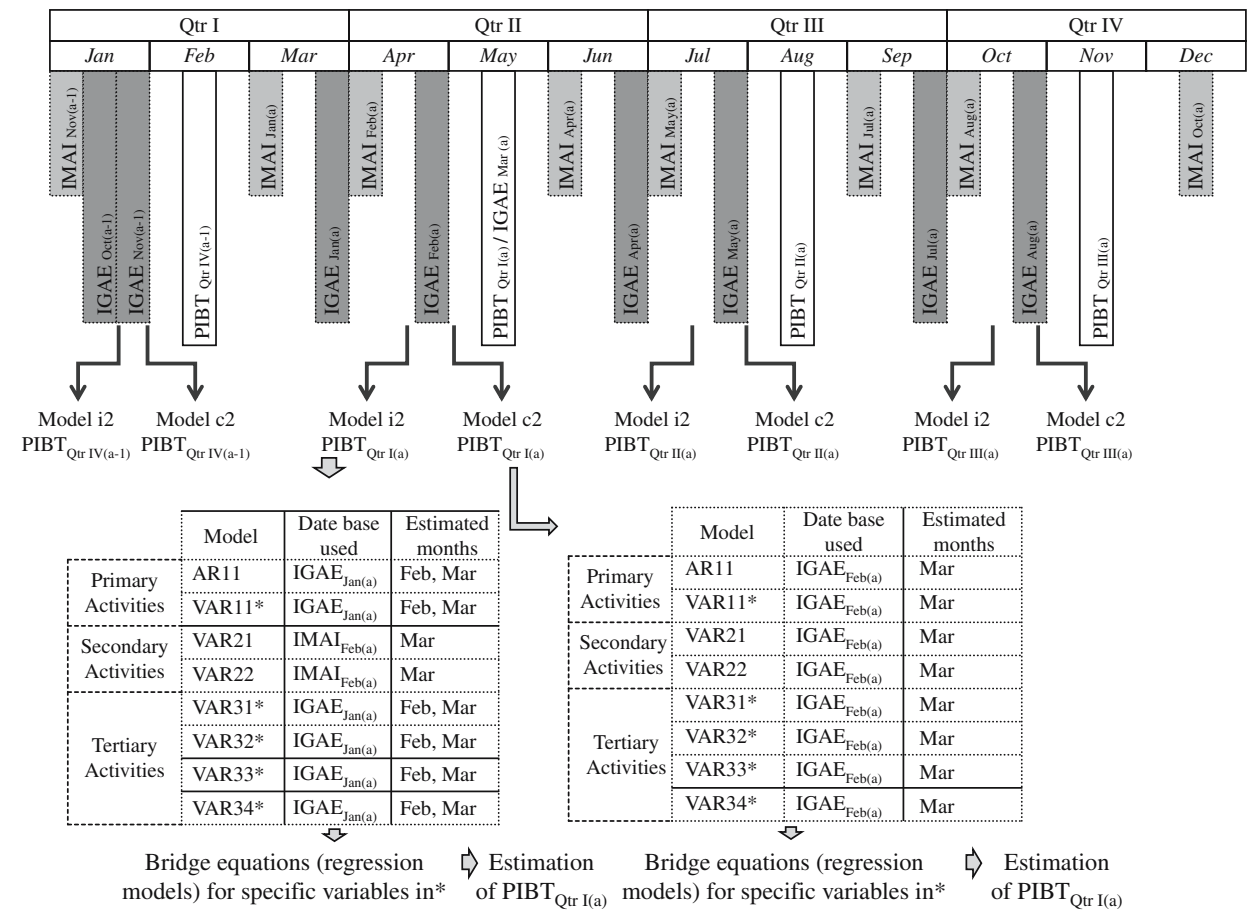

Appendix C. Estimation Schedule for the Simulations (Historical and in Real Time)

\begin{tabular}{|c|c|c|c|c|}
\hline $\begin{array}{l}\text { Simulation } \\
\text { No. and type }\end{array}$ & Data available & $\begin{array}{l}\text { Estimation } \\
\text { date }\end{array}$ & Model type & $\begin{array}{c}\text { PIBT } \\
\text { estimate }\end{array}$ \\
\hline 1 & IMAI & Apr/17/08 & i2 & 2008:I \\
\hline Historical & IGAE & Apr/29/08 & c2 & \\
\hline 2 & IMAI & Jul/17/08 & i2 & 2008:II \\
\hline Historical & IGAE & Jul/29/08 & $\mathrm{c} 2$ & \\
\hline 3 & IMAI & Oct/17/08 & $\mathrm{i} 2$ & 2008:III \\
\hline Historical & IGAE & Oct $/ 29 / 08$ & $\mathrm{c} 2$ & \\
\hline 4 & IMAI & $\mathrm{Jan} / 16 / 09$ & i2 & 2008:IV \\
\hline Historical & IGAE & $\mathrm{Jan} / 28 / 09$ & c2 & \\
\hline 5 & IMAI & Apr/17/09 & i2 & 2009:I \\
\hline Historical & IGAE & Apr/28/09 & c2 & \\
\hline 6 & IMAI & Jul/17/09 & i2 & 2009:II \\
\hline Historical & IGAE & Jul/28/09 & c2 & \\
\hline 7 & IMAI & Oct/16/09 & i2 & 2009:III \\
\hline Historical & IGAE & Oct/28/09 & $\mathrm{c} 2$ & \\
\hline 8 & IMAI & $\mathrm{Jan} / 12 / 10$ & i2 & 2009:IV \\
\hline Historical & IGAE & $\mathrm{Jan} / 27 / 10$ & c2 & \\
\hline 9 & IMAI & Apr/12/10 & i2 & 2010:I \\
\hline Historical & IGAE & Apr/27/10 & $\mathrm{c} 2$ & \\
\hline 10 & IMAI & Jul/12/10 & i2 & 2010:II \\
\hline Real time & IGAE & $\mathrm{Jul} / 27 / 10$ & c2 & \\
\hline
\end{tabular}




\section{References}

Armah, N.A. and Swanson, N.R. (2008). Seeing Inside the Black Box: Using Diffusion Index Methodology to Construct Factor Proxies in Large Scale Macroeconomic Time Series Environments. Federal Reserve Bank of Philadelphia Working Paper No. 08-25. Aruoba, S.B., Diebold, F.X., and Scotti, C. (2009). Real-Time Measurement of Business Conditions. Journal of Business and Economic Statistics, 27, 417-427.

Baffigi, A., Golinelli, R., and Parigi, G. (2004). Bridge Model to Forecast the Euro Area GDP. International Journal of Forecasting, 20, 447-460.

Bloem, A.M., Dippelsman, R.J., and Maehle, N.O. (2001). Manual de Cuentas Nacionales Trimestrales. Conceptos, fuentes de datos y compilación. Washington, D.C. International Monetary Fund.

Clements, M.P. and Galvao, A.B. (2008). Macroeconomic Forecasting with MixedFrequency Data: Forecasting Output Growth in the United States. Journal of Business and Economic Statistics, 26, 546-554.

Diebold, F.X. (2001). Elements of Forecasting, (2nd Edition). Cincinnati: South-Western.

Diron, M. (2006). Short-Term Forecasts of Euro Area Real GDP Growth. An Assessment of Real-Time Performance Based on Vintage Data. European Central Bank Working Paper No. 622.

Enders, W. (2003). Applied Econometric Time Series, (2nd Edition). New York: Wiley.

Fair, R.C. and Shiller, J. (1990). Comparing Information in Forecasts from Econometric Models. The American Economic Review, 80, 375-389.

Forni, M. and Reichlin, L. (1998). Let's Get Real: A Dynamic Factor Analytical Approach to Disaggregated Business Cycle. Review of Economic Studies, 65, 453-474.

Forni, M., Hallin, M., Lippi, M., and Reichlin, L. (2005). The Generalized Dynamic Factor Model: One-Sided Estimation and Forecasting. Journal of the American Statistical Association, 100, 830-840.

Geweke, J. (1977). The Dynamic Factor Analysis of Economic Time Series. Latent Variables in Socio-Economic Models, D.J. Aigner and A.S. Goldberger (eds). Amsterdam: North-Holland.

Ghysels, E., Santa-Clara, P., and Valkanov, R. (2004). The MIDAS Touch: Mixed Data Sampling Regression Models. Unpublished manuscript, University of North Carolina. Available at: http://www.unc.edu/eghysels (accessed April, 2013).

Ghysels, E. (2012). Macroeconomics and the Reality of Mixed Frequency Data. Chapel Hill: Manuscript, University of North Carolina.

Granger, C.W.J. (1996). Can We Improve the Perceived Quality of Economic Forecasts? Journal of Applied Econometrics, 11, 455-473.

Guerrero, V.M. (1993). Time Series Analysis Supported by Power Transformations. Journal of Forecasting, 12, 37-48.

INEGI (2007). Sistema de Clasificación Industrial de América del Norte, México. SCIAN 2007, (Third edition). México: Instituto Nacional de Estadística, Geografía e Informática.

Katz, A.J. (2006). An Overview of BEA's Source Data and Estimating Methods for Quarterly GDP. Paper prepared for the 10th OECD-NBS Workshop on National Accounts. Paris, France, November 6-10, 2006. 
Kitchen, J. and Monaco, R. (2003). Real-Time Forecasting in Practice: The U.S. Treasury Staff's Real-Time GDP Forecast System. Business Economics, October, 10-19.

Klein, L.R. and Sojo, E. (1989). Combinations of High and Low Frequency Data in Macroeconometric Models. Economics in Theory and Practice: An Eclectic Approach, L.R. Klein and J. Marquez (eds). Norwell, MA: Kluwer Academic Publishers.

Koenig, E.F., Dolmas, S., and Piger, J. (2003). The Use and Abuse of Real-Time Data in Economic Forecasting. The Review of Economics and Statistics, 85, 618-628.

Kuzin, V., Marcellino, M., and Schumacher, Ch. (2010). Pooling Versus Model Selection for Nowcasting with Many Predictors: An Application to German GDP. Presented at the 6th Colloquium on Modern Tools for Business Cycle Analysis. Luxembourg, 26-29 September. Available at: epp.eurostat.ec.europa.eu/portal/page/portal/euroindicators conferences/6th_colloquium/ program_papers (accessed April 2013).

Lütkepohl, H. (2005). New Introduction to Multiple Time Series Analysis. Berlin: Springer-Verlag.

Maravall, A. (1993). Stochastic Linear Trends, Models and Estimators. Journal of Econometrics, 56, 5-37.

Mazzi, G.L. and Montana, G. (2009). A System of Rapid Estimates to Improve Real Time Monitoring of the Economic Situation: The Case of the Euro Area. Presented at the Seminar on Timeliness, methodology and comparability of rapid estimates of economic trends. Ottawa, 27-29 May. Available at: unstats.un.org/unsd/nationalaccount/workshops/2009/ottawa/ac188-2.asp (accessed April 2013).

Mazzi, G.L., Mitchell, J., Mouratidis, K., and Weale, M. (2009). The Euro-Area Recession and Nowcasting GDP Growth Using Statistical Models. Presented at the International Seminar on Early Warning and Business Cycle Indicators. Scheveningen, 14-16 December. Available at: unstats.un.org/unsd/nationalaccount/workshops/2009/netherlands/ac202-2.asp (accessed April 2013).

Mustapha, N. and Djolov, G. (2010). The Development and Production of GDP Flash Estimates in a Newly Industrialised Country: The Case of South Africa. Presented at the 6th Colloquium on Modern Tools for Business Cycle Analysis. Luxembourg, 26-29 September. Available at: epp.eurostat.ec.europa.eu/portal/page/portal/euroindicators_ conferences/6th_colloquium/ program_papers (accessed April 2013).

Newey, W.K. and West, K. (1987). A Simple Positive Semi-Definite Heteroscedasticity and Autocorrelation Consistent Covariance Matrix. Econometrica, 55, 703-708.

Rünstler, G. and Sédillot, F. (2003). Short-Term Estimates of Euro Area Real GDP by Means of Monthly Data. European Central Bank Working Paper No. 276.

Sánchez, I. and Peña, D. (2001). Properties of Predictors in Overdifferenced Nearly Nonstationary Autoregression. Journal of Time Series Analysis, 22, 45-66.

Stock, J.H. and Watson, M.W. (2002). Macroeconomic Forecasting Using Diffusion Indices. Journal of Business and Economic Statistics, 20, 147-162.

UNECE Secretariat (2009). Rapid Estimates of GDP in CIS and Western Balkan Countries. Presented at the Seminar on Timeliness, methodology and comparability of rapid estimates of economic trends. Ottawa, 27-29 May. Available at: unstats.un.org/ unsd/nationalaccount/workshops/2009/ottawa/ac188-2.asp (accessed April 2013). 
Zadrozny, P.A. (1990). Estimating a Multivariate ARMA Model with Mixed-Frequency Data: An Application to Forecasting U.S. GNP at Monthly Intervals. Federal Reserve Bank of Atlanta Working Paper No. 90-6.

Zheng, I.Y. and Rossiter, J. (2006). Using Monthly Indicators to Predict Quarterly GDP. Bank of Canada Working Paper 2006-26.

Received November 2011

Revised September 2012

Accepted May 2013 